\title{
Sistematização de conceitos ergonômicos e semióticos para projetos de interfaces gráficas do usuário
}

\section{Systematization of ergonomic concepts and semiotic projects for graphic user interfaces}

\section{SCHULENBURG, Roy I Mestre em Design}

Universidade da Região de Joinville I UNIVILLE royzera@gmail.com

\section{PEZZINI, Marina Ramos I Mestre em Arquitetura}

Universidade da Região de Joinville I UNIVILLE marinapzn@gmail.com

O presente artigo tem como objetivo a sistematização de conceitos de vários autores sobre os conceitos ergonômicos e semióticos para o projeto de interfaces gráficas do usuário. Apresentam-se conceitos ergonômicos e semióticos aplicados a interfaces gráficas do usuário com foco na ergonomia, usabilidade, estrutura, semiótica e cognição. Para tanto, realizou-se um levantamento bibliográfico de conceitos sobre interação e seus níveis relacionados à interface, suas aplicações ergonômicas, a usabilidade com a eficácia, eficiência e satisfação de uso do sistema e aplicações semióticas, o uso de metáforas visuais para a construção e cognição para o entendimento.

Palavras Chave: Interface gráfica do usuário. Ergonomia cognitiva. Semiótica.

\section{Abstract}

This article aims to systematize concepts of various authors on the ergonomic and semiotic concepts for the design of graphical user interfaces. Presents ergonomic concepts and applied semiotic graphical user interfaces with a focus on ergonomics, usability, structure, semiotics and cognition. Therefore, we performed a literature review of concepts and their interaction levels related to interface their applications ergonomic usability with effectiveness, efficiency and satisfaction of using semiotic system and applications, the use of visual metaphors for the construction and cognition for understanding.

Keywords: Graphical user interface. Cognitive ergonomics. Semiotics 


\section{INTRODUC̣̃̃O}

\section{Interface Gráfica do Usuário}

A capacidade semântica de uma interface pode ser analisada sob quatro dimensões complementares: uma topologia, na qual a relação governada é feita por uma conectividade, proximidade ou um "espaço" específico: associações, ligações, caminhos, portas; uma semiótica, que relaciona imagens, signos e mensagens de todas as formas; uma axiologia; que se apresenta na relação entre as representações e os valores; e uma energética, que mede a intensidade destes valores (LÉVY, 1996).

Estas relações feitas a partir de linguagens e objetos escolhidos para transmitir algum tipo de informação dentro de uma interface têm vínculos diretos com fundamentos do design. $O$ designer é também um mediador da linguagem matemática do software tornando-a interpretável para o usuário, além de se preocupar com as distinções gráficas da ferramenta, como forma, cor, tamanho, posição, orientação, entre outras, a preocupação com a percepção e interpretação das informações, seja isto feito por uso de metáfora, ícone, signo ou cognição, também é relevante. A relação de interface-usuário é uma relação semântica, caracterizada pelo significado e a expressão, e não por força física (MACEDO FILHO, 2005).

A eficácia de uma interface está na expressão do que constitui a semântica do objeto graficamente representado. $O$ objeto deve parecer aquilo que é, ou se comportar de maneira coerente com o que sugere visualmente. É possível relacionar quatro enfoques principais da interface com o design, que são: Arquitetura da informação, que tem finalidade em estruturar o conteúdo; Interação, que busca estruturar o comportamento entre homem e sistema; informação, que se preocupa na clareza das informações e Design de Interface, cujo objetivo é construir a estrutura visual do sistema (MARTINS, 1998; OLSEN, 2003)

A função da interface é facilitar e intermediar a relação interativa entre homem e máquina, garantindo que a atenção do usuário seja focada na tarefa que ele deseja executar. A ergonomia trata a interação humana de um sistema como "[...] tecnologia projetual das comunicações entre homens e máquinas, trabalho e ambiente". Portanto a interface pode ser homem-máquina, homemambiente, homem-sistema (MORAES; MONT'ALVÃO, 2009).

Interface é um dispositivo que estabelece comunicação entre dois sistemas distintos, com a função de facilitar e intermediar essa troca de informações para que a tarefa seja executada com eficiência. Sendo a interface uma metáfora 
tradutora, seus principais elementos são os códigos linguísticos pelos quais ela se comunica. Esses podem ser divididos para fins projetuais em duas categorias principais: códigos visuais e sequênciais. Em livros, a utilização da linguagem é de imagem fixa e texto. Já no ciberespaço, ela foi ampliada para códigos linguísticos: ferramentas para a construção de diferentes realidades por meio da linguagem (ROYO, 2008).

\section{Interação}

Uma das características de qualquer interface é promover níveis de interação. A interação se caracteriza pelo contato humano com um sistema através de uma interface. É a essência da sua função.

O apelo do interativo vem sendo fortemente utilizado no desenvolvimento de novos produtos. Trazer o usuário relacionando uma participação dele com o produto tem se tornado cada vez mais evidente no mercado. Isto gera uma banalização do termo "interatividade", perdendo a precisão do sentido (SILVA, 2005). O conceito de interatividade surge da interação, no caso social, a relação recíproca entre as diferentes pessoas ou grupos. O termo ganha corpo com o surgimento de novas tecnologias de informação, passando a ter uma conotação de interação entre indivíduos e sistema. A interatividade não é apenas uma questão relacionada à tecnologia, ela implica física, psicológica e sensivelmente o usuário. São casos em que os sentidos são transformados em impulsos digitais e a experiência perceptiva é como se tocasse o ambiente virtual (PLAZA, 1993; DOMINGUES, 2002).

O usuário que interage com a interface percorre caminhos através de suas escolhas. Em alguns momentos por influências, em outros por intermédio de uma dada solicitação, mas sempre percorrendo ambientes do seu discernimento, da sua escolha, com isso provocando um rastro, um caminho, uma documentação virtual. É dessa lógica criada pelo usuário ao imergir na web que ele também se torna construtor do ambiente, não apenas atuando como o usuário, mas como parte do sistema em si (LEÃO, 2005). O autor comenta ainda sobre o percurso criado pelo usuário na interação hipermidiática, definindo em três conceitos: actema, episódio e sessão.

O actema é a unidade básica do hipertexto e corresponde ao ato de se seguir um link. Quando o leitor de um hipertexto "clica" sobre um link ele é levado para outra parte do documento, ou mesmo para outro ponto da rede. Esse estabelecimento de um elo, essa atividade de unir dois pontos distintos é o actema. $O$ episódio é o conjunto de actemas que criam coerência da mente do 
leitor. A sessão compreende a atividade do leitor em sua continuidade (LEÃO, 2005).

A possibilidade de permitir ao usuário trocar experiências e influenciar o conteúdo ou as formas de comunicação de um sistema, individual ou coletivamente, é definida como interativa. No caso de estrutura virtual de rede social, ambas as colocações são cabíveis, uma vez que o plano em que se constitui lhe permite projetar extensões sensoriais dentro de um ambiente tecnológico utilizando como recurso a interface.

\section{Aplicação Ergonômica}

A relação de interação entre interface e homem tem sua base na ergonomia, que tem a finalidade de otimizar o desempenho do sistema. Para um ambiente virtual interativo, a relevância da ergonomia está em estudar de que maneira se dá a interação, identificar necessidades e estabelecer regras e definições com o objetivo de tornar o sistema adequado ao usuário, levando em conta suas limitações na relação com o produto.

Este estudo mais detalhado da relação entre usuário e sistema pode ser dividido em dois eixos principais. Quanto à utilidade do sistema, que trata dos recursos funcionais e de performance necessários para a realização das tarefas a que foi concebido; e quanto à usabilidade, que relaciona a qualidade do sistema em facilitar o manuseio e o aprendizado (ABRAHÃO, 2005).

A função estética da interface também encontra razão na ergonomia. Além das definições de layout, como formas, cores, alinhamentos, entre outros, transformam a informação visual em expressão e carregam o sistema de informações a fim de orientar o usuário. Estes princípios centrados no usuário são, conforme Martins (1998, p.46):

\footnotetext{
a necessidade de consistência na interface, a necessidade absoluta de retorno para o usuário, visibilidade da informação, orientações para usuários principiantes. A simplicidade facilita a compreensão do usuário, o uso e o aprendizado da interface.
}

O projeto ergonômico da interface leva em consideração funções práticas, estéticas e de usabilidade. O embasamento nestes três fatores fornece à interface a capacidade de atender as necessidades dos usuários e se apresentar 
de maneira mais eficaz e eficiente.

\section{ESTRUTURAC̣ÃO E APRESENTAC̣ÃO}

A estrutura encara a interface da maneira como ela se mostra para o usuário, buscando organizar os espaços, definir as funções, os objetivos e as formas de localização para relacionar um ambiente a outro, dar dinamismo a leitura e otimizar a navegação na interface. A apresentação leva em conta as características visuais do projeto, relacionando a estrutura da interface com as tecnologias móveis.

Para Hassanein e Head (2003, apud ITO, 2007) existem cinco principais tipos de classificação:

- Menu Hierárquico: o menu se apresentada por meio de uma série de itens, que quando acionados, dão origem a subitens;

- Códigos Curtos: o usuário escolhe as opções de menu por códigos numéricos, fazendo relação com as letras do alfabeto.

- Baseada em Árvore: a árvore é composta por nós e folhas. A escolha de um nó expande as folhas, proporcionando a escolha de subopções;

- Baseada em Tabela: representação das opções por ícones ou símbolos, proporcionando assim a representação de uma maior quantidade de informações em telas pequenas;

- Baseada em Discurso: selecionar verbalmente itens de um menu ou um comando de entrada para ativar diretamente uma função.

A apresentação da estrutura pode também sofrer alterações para otimização da leitura e navegação. Ito (2007) explora dois conceitos ao falar deste tema:

- Layout Original: nesta forma de apresentação o layout é exibido por completo, com todas as informações no plano visual.

- Layout Reduzido: apresenta o conteúdo formatado ao tamanho da tela.

O desempenho do sistema está diretamente ligado à sua capacidade de se adaptar aos mais diversos suportes. A apresentação da estrutura deve ser 
capaz de atender as necessidades do usuário da maneira que melhor Ihe convir, independentemente do local de onde este a acessa.

Para que uma organização seja eficaz em qualquer estrutura a fim de facilitar o uso do sistema para o usuário. Cybis (2007) define o agrupamento e distinção de itens como um serviço "intuitivo" da interface, classificando-os por localização, que permite ao usuário fazer grupamentos a partir das localizações das informações, e por formato, que permite ao usuário perceber rapidamente as similaridades ou diferenças das informações.

Toda esta estrutura contém uma série de características e recursos que devem ser considerados. Segundo Shneiderman (1998), para se ter uma ideia mais clara sobre interface na questão de apresentação visual e estrutural, algumas diretrizes referenciam o caminho do designer. Cada projeto tem suas necessidades, mas algumas guias devem ser consideradas para:

- Palavras e Ícones;

- Terminações, abreviações e capitulações;

- Estilos de fontes Ícones, gráficos e espessura de linhas;

- Uso de cores, backgrounds e destaques;

- Questões de layout;

- Seleção de menus, formas e caixas de diálogo;

- Mensagens de alerta, de informação e de erro;

- Margens e espaços neutros;

- Devices;

- Teclado, display, controle do cursor;

- Áudio, alertas sonoros, comandos de voz, interação ao toque e outros;

- Sequência de ações;

- Clicar, arrastar, soltar;

- Sintaxe e semântica dos comandos; 


\section{- Comandos programados.}

Este estudo se limitou na interação entre homem e interface, tendo questões como: teclado, display, cursor e outras encaradas de maneira conceitual. Os aspectos citados acima são guias de orientação para construção da interface, e segui-las não garante êxito do projeto. Existem questões que relacionam percepção e preferência estética ao projeto gráfico da interface. Para que não se criem ruídos nas mensagens que possam reduzir significativamente a usabilidade do projeto, a busca pela simplicidade mostra-se a solução ideal. Excessos de detalhes, informações irrelevantes e a busca por uma representação fiel da realidade devem ser evitadas para favorecer o uso da interface.

\section{Usabilidade}

Usabilidade, na interação entre homem e o sistema, como o próprio nome já sugere, tem relação com o uso que se faz da interface. O objetivo é que o sistema seja eficaz, eficiente e que promova satisfação de uso. Segundo Preece, Rogers e Sharp (2005), ela implica em otimizar as interações estabelecidas pelas pessoas com produtos interativos, de modo a permitir que estas realizem suas atividades.

Cybis (2007) define usabilidade como sendo a qualidade dos programas e aplicações. Não uma qualidade intrínseca dos sistemas, mas um acordo entre a interface e as características do usuário ao buscar determinadas funções de uso.

Em estruturas da mente: a teoria das inteligências múltiplas, Gardner (apud LEÃO, 2005) apresenta dois aspectos básicos: a capacidade de manejar longas cadeias de raciocínio (seguir uma determinada sequência); e criar uma nova ordem. Portanto, indica-se inicialmente avançar, passo a passo, no raciocínio, mantendo a sequência das etapas. Basicamente, o problema não é descobrir qual caminho seria o correto, mas adotar um procedimento e avançar de modo coerente.

Com intuito de definir a maneira mais coesa de fazer o sistema se comunicar com o usuário. Shneiderman (1998) define cinco quantificadores de fatores humanos como centrais para avaliação:

- Tempo de aprendizado: Quanto tempo leva o membro da comunidade para aprender como usar os comandos do programa? 
- Desempenho (Performance): Quanto tempo o usuário leva para realizar as ações propostas?

- Taxa de erros por usuário: Quantos e quais tipos de erros as pessoas cometem ao realizar as ações à elas propostas?

- Retenção ao longo do tempo (Memorização): Por quanto tempo o usuário mantém o conhecimento de uso? Por uma hora, um dia ou uma semana?

- Satisfação subjetiva: O quanto os usuários demonstram gostar dos vários aspectos do sistema?

Além dos fatores humanos, cuja mensuração é fundamental para realização do projeto, os fatores relacionados à usabilidade da interface recorrem de igual atenção. Preece, Rogers e Sharp (2005) dividem usabilidade em seis metas:

- Eficácia é uma meta bastante geral se refere a quanto um sistema é bom em fazer o que se espera dele;

- Eficiência se refere à maneira como o sistema auxilia os usuários na realização de suas tarefas;

- Segurança implica proteger o usuário de condições perigosas e situações indesejáveis.

- Utilidade refere-se à medida na qual o sistema propicia o tipo certo de funcionalidade, de maneira que os usuários possam realizar aquilo de que precisam ou que desejam.

- Capacidade de aprendizagem se refere à quão fácil é aprender a usar o sistema. É fato sabido que as pessoas não gostam de passar muito tempo aprendendo como fazê-lo. Preferem utilizá-lo logo e tornarem-se competentes para realizar tarefas sem muito esforço. Tal fato se verifica especialmente com relação aos produtos interativos de uso diário;

- Capacidade de memorização: refere-se à facilidade de lembrar como utilizar um sistema depois de ter aprendido como fazê-lo. Algo especialmente importante para sistemas interativos que não são utilizados com muita frequência.

Para usabilidade aplicada na relação entre os dois mundos, o do usuário e do sistema, Nielsen (1993) cita alguns aspectos fundamentais: 
- Visibilidade do status do sistema: o sistema mantém os usuários sempre informados sobre o que está acontecendo, fornecendo um feedback adequado, dentro de um tempo razoável;

- Compatibilidade do sistema com o mundo real: o sistema fala a linguagem do usuário utilizando palavras, frases e conceitos familiares;

- Controle do usuário e liberdade: fornece maneiras de permitir que os usuários saiam facilmente dos lugares inesperados em que se encontram;

- Consistência e padrões: evita fazer com que os usuários tenham que pensar se palavras, situações ou ações diferentes significam a mesma coisa;

- Prevenção de erros: onde possível, impede a ocorrência de erros;

- Reconhecimento em vez de memorização: tornar objetos, ações e opções visíveis;

- Flexibilidade e eficiência de uso: fornece aceleradores invisíveis aos usuários inexperientes, os quais, no entanto, permitem aos mais experientes realizar tarefas com mais rapidez;

- Estética e design minimalista: evita o uso de informações irrelevantes ou raramente necessárias;

Entre as relações que implicam entre usuário e interface os fundamentos da usabilidade se mostram fundamentais para fidelização de determinado público ao uso do sistema. Clareza e objetividade na transmissão de mensagens (linguística ou visualmente), relações entre preferências visuais, padrão de códigos e referências ao mundo real transferem grande capacidade na aplicação deste tipo de projeto.

\section{Aplicação Semiótica}

A clareza das informações de qualquer sistema não se restringe às suas propriedades visuais. Toda e qualquer informação, além de ser percebida, necessita ser compreendida pelo usuário no momento em que este faz uso do sistema.

A semiótica propõe o estudo dos signos e dos sistemas sígnicos. Signo é qualquer coisa que representa ou identifique algo para alguém. No campo de 
interfaces de sistemas, tudo são signos, e, portanto se presta a um tratamento semiótico (MARTINS, 1998).

Existe a necessidade de um estudo dos signos em um sistema informatizado. Partindo do pressuposto de que sistemas informatizados são ferramentas simbólicas e que sua construção se dá basicamente para seus usuários. Portanto, o estudo do processo de significação nestes ambientes pode tornar a comunicação com o sistema mais acessível. A interface deve orientar o usuário evitando que este se frustre. A produtividade cresce na medida inversa do esforço que o usuário tem de fazer para compreender o sistema. (ANDERSON, 1990; MARTINS, 1998).

Nossa capacidade de interpretação de códigos ou mensagens está relacionada ao tipo de informação que recebemos. Esta variedade de tipos de mensagem bombardeia nosso corpo e cérebro com uma infinidade de relações possíveis a serem feitas. Para entender com mais clareza estes tipos de relações em uma abordagem relacionada a sistemas. Cybis (2007) define nossa capacidade de percepção em quatro tópicos: estímulo, sensação, percepção e cognição. Estímulo é um fenômeno natural que reage com órgãos sensitivos humanos. A sensação é uma resposta neurofisiológica a um estímulo sensorial. Percepção caracteriza o conjunto de mecanismos que organizam as sensações. E cognição se refere aos processos de interpretação e significação destas sensações organizadas.

Reduzir o esforço interpretativo do usuário no uso do sistema demonstra a importância do uso de recursos facilitadores na transmissão de mensagens. A eficiência na interpretação da informação está diretamente relacionada à bagagem cultural do receptor, uma vez que os níveis perceptivos citados acima se mostram como uma via que transita em dois sentidos, do sistema para o usuário e do usuário para o sistema.

Utilizar recursos de linguagem que aproximem a linguagem virtual à realidade do usuário de forma análoga se apresenta como uma fortecaracterística de um sistema interativo e faz-se necessárias analogias metáforas ou modelos de aproximação que possibilite a análise, reflexão, crítica e conhecimento científico da estruturação como linguagem (MARTINS, 1998; LEÃO, 2005).

Ao designer cabe utilizar-se de aspectos com base semiótica que favoreçam a interpretação do usuário e que podem conferir eficácia no aspecto comunicativo de um sistema. O uso de metáforas, ícones e cognição são capazes de traduzir as informações contidas no sistema para o usuário final. 


\section{Metáforas Visuais}

A metáfora nos sistemas informatizados se apresenta com caráter facilitador na maneira de navegação do usuário no sistema; ela localiza e indica uma relação entre mundo real, com detalhes conhecidos pelo usuário, com o mundo virtual, que simula os conceitos destes detalhes. Alguns dos exemplos mais comuns encontrados hoje estão no de salas de bate papo, onde a palavra sala toma conotação de espaço diferenciado, em que a pessoa entra para fazer determinado tipo de atividade. Este tipo de relação encurta o processo cognitivo e permite uma rápida interpretação da função e do objetivo de determinada ação que deva ser tomada pelo usuário.

Preece, Rogers e Sharp (2005) descreve que modelos conceituais se dão em termos de metáforas da interface; o sistema deve se assemelhar a alguma forma e a aspectos da entidade física, mas deve ter comportamento e propriedades próprias. O mecanismo sugere uma comparação entre um objeto físico e uma ação rotineira, e combina conhecimento familiar com novos conceitos. Este modelo é sugerido para que se tome o termo metáfora não como uma cópia da realidade - seja de função, ação ou objetivo - mas sim como uma relação entre características familiares, visuais ou funcionais, com a função que a interface necessita traduzir para o usuário.

De modo geral, a utilização de metáforas permite que uma quantidade menor de informação precise estar explícita. Esta otimização interpretativa do usuário mostra a eficiência que a metáfora tem neste tipo de aplicação (MARTINS, 1998). Preece, Rogers e Sharp (2005) ressalta que "as metáforas de interface provaram ser bastante bem sucedidas, oferecendo aos usuários um mecanismo familiar para orientá-los e auxiliá-los a entender e aprender como utilizar um sistema".

Sobre essa familiaridade, Martins (1998) comenta que a metáfora, sob um enfoque cognitivo, é bastante valiosa, uma vez que traz conceitos conhecidos do usuário, sem ter de explicitá-los um a um. A metáfora ativa, através de reconhecimento de uma situação conhecida, a compreensão do usuário, ela funciona como elemento de ativação sígnica.

Algumas precauções, porém, devem ser tomadas na utilização de metáforas. Os problemas as que elas podem levar, conforme Cooper e Reimann (2003 apud JACOBER, 2007, p.42):

- Metáforas não são infinitamente extensíveis. Conforme o aumento da complexidade, manter a analogia para as novas funcionalidades pode influenciar negativamente na interação; 
- Metáforas podem distanciar o modelo mental do usuário do modelo estrutural do sistema. As metáforas não possuem apenas características análogas ao sistema, mas outras características que não tem equivalência nesse. Isso pode levar os usuários a imaginar funções diferentes do que o sistema possui;

- Metáforas perdem a funcionalidade se não houver tradução. Para usuários fora da língua onde foram concebidos, pode ocorrer de aprenderem primeiro como o sistema funciona, para depois descobrir a tradução da metáfora. O que a torna dispensável. Fato que pode ocorrer também quando bagagem sóciocultural for muito diferente daquela do projetista.

Para adequação metafórica da mensagem, Bonsiepe (1997) oferece uma lista de conceitos para construção de figuras visuais/verbais:

- Analogia: uma comparação verbal é transferida ao campo visual através de sinais semânticos equivalentes;

- Metonímia: um significado verbal é relacionado com outro significado mediante uma conexão temática;

- Sinédoque: uma parte representa o todo;

- Especificação: o sinal visual é acompanhado de um mínimo de texto para outorgar-Ihe maior precisão semântica;

- Fusão: um sinal visual é integrado num sistema de sinais em forma de super-sinal;

- Paralelismo: informações visuais e verbais referem-se ao mesmo significado;

- Transferência ou comunicação por associação: transferência de uma série de sinais verbais para ilustrar uma imagem (contexto associativo);

- Inversão metafórica: a tensão entre significado primário e secundário é utilizada para mostrar o significado primário dos sinais visuais e ao mesmo tempo tomá-lo no sentido literal;

- Exagero (hipérbole): o significado é visualizado numa maneira que excede o padrão normal;

- Tipograma: o significado da letra tipográfica é visualizado através da 
própria letra.

Uma construção com aspectos embasados em metáforas pode proporcionar maior facilidade de interpretação por parte do usuário, além de aproximar a linguagem de sua realidade; fatos que conferem grande importância no projeto de interface, pois visam exclusivamente à eficiência do sistema e a satisfação do leitor.

\section{Ícones, Índices e Símbolos}

Outra possibilidade capaz de encurtar o tempo interpretativo do usuário, além das metáforas, são recursos como ícones e símbolos, que tem grande poder representativo e são altamente necessários na construção de uma interface. Assim como a metáfora, sua função é identificar espaços e objetivos dentro de um sistema, mas diferenciam-se por ter um caráter mais visual dentro do ambiente.

Fernandes (2004) complementa esse pensamento relacionando ícones, índices e símbolos e sua finalidade como guia funcional e estético para interfaces gráficas, funcionando como um sistema de signos.

Peirce (2000) diz que a qualidade do ícone é sua similaridade com o objeto que representa, ele representa apenas uma parte da semiose na qual se evidenciam aspectos qualitativos do objeto; a do índice é ser uma causa influenciada por este objeto em uma relação direta entre estas duas partes sem tratar-se de similaridade (uma nuvem escura significando chuva, embora sejam duas coisas totalmente distintas); e a do símbolo é ser convencional, abrem-se à multiplicidade e universalidade por seu alto grau de abstração.

É também com base nesse conceito representativo que o ícone possui que Cybis (2007) os classifica como componentes de um sistema de significados a fim de estabelecer relações entre conteúdo e expressão; relações estas que são baseadas em sua bagagem sócio-cultural. Chevalier (1980, apud Cybis, 2007) classifica os ícones, em diferentes tipos:

- Símbolo: uma representação gráfica concreta, motivada em objetos da realidade. Impressora, ferramentas.

- Emblema: figura adotada por convenção para representar uma ideia, um ser físico ou moral. Como exemplo cita bandeiras de países. 
- Atributo: um acessório característico usado para designar o todo. Garfo e faca para restaurante.

- Arquétipo: exemplar de uma categoria é usado para representar o conjunto dessa categoria. Histograma para possíveis escolhas em termo gráfico de dados.

- Analogia: explora semelhança ou relações entre seres ou noções essencialmente diferentes. Taça de cristal para fragilidade.

Estes sinais gráficos conseguem fazer rápida associação entre o objeto a que se está representando e a significância dada na sua relação com o usuário da interface, atribuindo eficiência e dinamismo na leitura do sistema.

\section{Cognição}

Cognição é conhecimento, seja ele construído ou em processo de evolução, a cognição envolve todas as etapas que realizamos a qualquer momento e em quaisquer atividades. $O$ processo de adquirir conhecimento envolve percepção, raciocínio, pensamentos, nossa linguagem, entre outros; todos estes são processos cognitivos.

Norman (2006) faz distinção entre dois modos mais gerais: cognição experiencial e cognição reflexiva. O primeiro tipo de cognição implica o estado mental em que percebemos, agimos e reagimos de maneira eficaz e sem esforço ao que acontece ao nosso redor. O segundo tipo envolve pensar, comparar e tomar decisões; é nesse tipo de cognição que se promovem as idéias e a criatividade. Norman afirma ainda que ambas são necessárias, mas ressalta que cada uma exige diferentes tipos de suporte tecnológico.

Dentro deste conceito, das relações que são feitas pelo ser humano e o que está presente ao seu redor, Weill-Fassina, Rabardel e Dubois (1993, apud ABRAHÃO et al., 2005) que afirmam que os processos cognitivos não são estáveis; eles se adaptam ao que deve ser realizado, nas condições existentes.

Um exemplo interessante adequado ao que foi disposto acima, de Lévy (1996), quando cita que um homem pré-histórico que vê um galho e reconhece-o pelo que é, mas a relação entre eles não para neste instante, pois, ao dialetizar, o homem vê uma imagem duplicada; ele envesga os olhos sobre o galho e o imagina como um bastão, e neste momento o galho significa bastão; é um bastão virtual. Dentro deste exemplo, Lévy (1996) estabelece três conceitos: 
gramática, dialética e retórica. A gramática separa os elementos e organiza sequências, a dialética faz funcionar substituições e correspondências e a retórica separa seus objetivos de toda combinatória e referência para desdobrar o virtual como um mundo autônomo.

Em uma abordagem mais atual, Domingues (2002) relaciona a cognição na interatividade, que se dá por uma experiência performática do corpo em uma experiência guiada que implica em percepção e possessão do ambiente. Apoia-se ainda no conceito de cognição de Varela, que afirma que percepção e ação são inseparáveis e enquadra o corpo do ser humano e suas capacidades moto- sensoriais em um grande ambiente cultural. Assim, na interatividade o corpo é chamado a ser usado, e quando este está em ação, processa cognição como uma experiência vivida.

A fim de descrever os processos cognitivos com maior clareza, Preece, Rogers e Sharp (2005) relata sobre seis itens principais:

- Atenção: consiste no processo de selecionar coisas em que se concentrar dentre a variedade de possibilidades disponível. Envolve nossos sentidos auditivos e visuais.

- Percepção: refere-se como a informação é adquirida do ambiente pelos diferentes órgãos sensitivos e transformada em experiências como objetos, eventos, sons, gestos. Envolve outros processos como memória, atenção e linguagem.

- Memória: implica recordar vários tipos de conhecimento que nos permitem agir adequadamente.

- Aprendizado: pode ser considerado no que concerne a como utilizar uma aplicação baseada em computador ou como entender um dado tópico.

- Ler, falar e ouvir: as três formas de processamento da linguagem têm propriedades semelhantes e diferentes. Uma similaridade diz respeito ao significado das sentenças ou frases ser o mesmo, sem levar em consideração o modo em que estão expressas.

\section{- A resolução de problemas, o planejamento, o raciocínio e a tomada}

de decisão: são todos processos cognitivos que envolvem cognição reflexiva. Implicam pensar sobre o que fazer, quais são as opções e quais podem ser as consequências de se realizar uma dada ação.

O projeto de interface que aborde cognição deve atentar aos processos 
de percepção e compreensão do usuário. Para Martins (1998), na relação entre interação usuário-sistema e cognição, pretende-se compreender o raciocínio do usuário ao buscar os objetivos e tarefas, o que inclui a funcionalidade, a arquitetura e os processos metafóricos e metonímicos da linguagem do sistema.

A compreensão do sistema se relaciona com a prévia compreensão do usuário por parte do projetista. Entender o comportamento humano desde as relações mais primárias até as reflexões que este faz com os elementos do sistema é o que torna uma estrutura virtual em um processo eficaz na comunicação entre homem e sistema.

\section{Customização}

O termo customização é utilizado no que se refere a personalizar ou adaptar algum produto ou serviço para e/ou pelo seu usuário. O mesmo tem o caráter de adaptação de alguma coisa com a finalidade de adequar esta às necessidades de um determinado público. Em uma tradução não literal do termo, se aceita associar customização como adequação as preferências de seu público.

No cenário atual, percebem-se cada vez mais estratégias de propaganda e vendas direcionadas aos consumidores e suas particularidades; todos necessitam de identidade e unicidade. Estas características mostram a utilização de recursos customizáveis como ponto chave para sucesso de um produto. No caso do ambiente informatizado que se apresenta nas mais diversas formas para o público nos dias de hoje, trazer estes conceitos de identidade e unicidade e aplicá-los no sistema em que estes usuários vão interagir resulta em grande atratividade.

Ito (2007) cita a expansão tecnológica nos últimos anos e diz que esse crescimento torna difícil a tarefa de desenvolver interfaces. Para ele é necessário um estudo que identifique as necessidades e objetivos do usuário para projetar uma interface inteligente que se adapte às suas necessidades e preferências, e para isso, classifica as interfaces customizáveis em dois modelos:

- Interface Adaptativa. Apresentam-se promissoras na tentativa de superar os problemas atuais de complexidade na interação homem-computador. Para melhorar essa interação, são necessárias interfaces que sejam capazes de se adaptar às necessidades do usuário. Neste modelo o sistema analisa as ações e perfis do usuário e adapta-se automaticamente a ele. 
- Interface Adaptável. Considera-se adaptável a interface em que o usuário realiza as adaptações quanto requisita, ou seja, o usuário adapta o sistema a seu modo. Nesse contexto faz-se necessária a intervenção do designer limitando o nível de customização para que o sistema não saia do seu padrão.

Essas duas características propostas por Ito (2007) podem co-existir em um projeto de interface e suas aplicações tornam o ambiente mais convidativo ao usuário, uma vez que lhe concede conceitos de exclusividade e liberdade de opções e escolhas.

Entender as necessidades dos usuários e permitir sua diferenciação dos demais em uma estrutura de rede social é, além de atrativo, necessário para seu funcionamento. Um ambiente com diferentes personagens e diferentes preferências, sejam estas culturais, sociais, visuais ou particulares, reforça o vínculo de identidade; e conferir identidade é possibilitar identificação. Para tornar estes fatores possíveis, a interface deve estar bem preparada para receber o seu público e mostrar de forma clara qualquer possibilidade que permita criar vínculos mais pessoais com um produto informatizado. Isto the confere, além de preferência, fidelidade por parte de seus usuários.

\section{CONCLUSÃO}

Com a sistematização de conceitos foi possível revisar os conceitos e elementos ergonômicos e semióticos para o desenvolvimento de interfaces gráficas do usuário de maneira que seja possível auxiliar no desenvolvimento de interfaces mais eficazes, eficientes e oferecendo uma maior satisfação de uso. Espera-se que a sistematização de dados apresentada nesta pesquisa contribua para o desenvolvimento do conhecimento científico e de soluções técnicas na área de interfaces. 


\section{REFERÊNCIAS}

ABRAHÃO, Júlia Issy et al. Ergonomia, cognição e trabalho informatizado. Psicologia: teoria e pesquisa, Brasília, v. 21 n. 2, p. 163-171, maio/ago. 2005

ANDERSEN, Peter Bøgh. A theory of computer semiotics. Cambridge: Cambridge University Press, 1990.

BONSIEPE, Gui. Design: do material ao digital. Florianópolis: FIESC/IEL, 1997.

CYBIS, Walter. Ergonomia e usabilidade: conhecimentos, métodos e aplicações. São Paulo: Novatec, 2007.

DOMINGUES, Diana. Criação e interatividade na ciberarte. São Paulo: Experimento, 2002.

FERNANDES, Tissiane Nogueira Quevedo. Usabilidade de interfaces universitárias na Web: interações homem-computador. 2004. Monografia (Bacharelado em Ciências da Computação) - Universidade do Sul de Santa Catarina, Florianópolis.

ITO, Giani Carla et al. Uma arquitetura para geração de interfaces adaptativas para dispositivos móveis. São José dos Campos: INPE, 2007.

JACOBER, Eduardo Costa. Proposta e implementação de uma interface para motores de jogos interativa e centrada no usuário. 2007.

Dissertação (Mestrado em Engenharia) - Universidade de São Paulo, São Paulo.

JOHNSON, Steven. Interface culture - how new technology transforms the way we create and communicate. San Francisco: Harper Edge, 1997.

LÉVY, Pierre. Cibercultura. São Paulo: Ed. 34, 1999.

O que é o virtual? São Paulo: Ed. 34, 1996.

LEÃO, Lucia. O labirinto da hipermídia. 3. ed. São Paulo: Iluminuras, 2005.

MACEDO FILHO, Manoel Dantas. A relevância de interfaces gráficas amigáveis para jogos eletrônicos funcionais. In: SEMINÁRIO JOGOS 
ELETRÔNICOS, EDUCAÇÃO E COMUNICAÇÃO - CONSTRUINDO NOVAS TRILHAS, 1., 2005, Salvador. Anais... Salvador: UNEB, out. 2005. Disponível em:<http://www.comunidadesvirtuais.pro.br/ novastrilhas/textos/manoelfilho.pdf>. Acesso em: 20 maio 2012.

MARTINS, Isa Haro. Um instrumento de análise semiótica para linguagens visuais de interfaces. 1998. Tese (Doutorado em Informática) - Departamento de Informática Pontifícia Universidade Católica do Rio de Janeiro, Rio de Janeiro.

MORAES, Anamaria de; MONT'ALVÃO, Cláudia. Ergonomia: conceitos e aplicações. 4. ed. Rio de Janeiro: 2AB, 2009.

NIELSEN, Jakob. Usability engineering. Boston: Academic Press, 1993.

NORMAN, Donald. Design do dia a dia. São Paulo: Rocco, 2006.

OLSEN, George. Approaches to user experience design. 2003.

Disponível em: <http://boxesandarrows.com/files/banda/expanding_ the_approaches_to_user_experience/uxapproachesmodel.pdf $>$. Acesso em: 16 maio 2012.

PEIRCE, Charles Sanders. Semiótica. 3. ed. São Paulo: Perspectiva, 2000.

PLAZA, Júlio. As imagens de terceira geração, tecno poéticas. In: PARENTE, André (Org.). Imagem-Máquina. São Paulo: Ed. 34, 1993. p. 72-88.

PREECE, Jennifer; ROGERS, Yvonne; SHARP, Hellen. Design de interação: além da interação homem-computador. Porto Alegre: Bookman, 2005.

ROYO, Javier. Design digital. São Paulo: Rosari, 2008.

SCHNEIDERMAN, Ben. Designing the user interface: strategies for effective human- computer interaction. 3. ed. Boston: Addison-Wesley, 1998.

SILVA, Marco. Cibercultura e interatividade: desafios à imaginação criadora do professor. 2005. Disponível em:<http://www.moodle. ufba.br/file.php/8/moddata/forum/122/496/Cibercultura_e_interati vidade_marco_msm.com.br_doc>. Acesso em: 7 maio 2012. 
Recebido em: 09/03/2013.

Aceito em: 23/04/2013. 